\title{
Tunable Synthesis of Ultrathin BiOCl 2D Nanosheets for Efficient Photocatalytic Degradation of Carbamazepine upon Visible-Light Irradiation
}

\author{
Shuo Xu $\mathbb{D}^{1},{ }^{1}$ Xiaoya Gao, ${ }^{2}$ Wenfeng Xu $\mathbb{D},{ }^{1}$ Pengfei Jin $\mathbb{D}^{1},{ }^{1}$ and Yongmei Kuang ${ }^{1}$ \\ ${ }^{1}$ Department of Pharmaceutical Science, Beijing Hospital, National Center of Gerontology, Institute of Geriatric Medicine, \\ Chinese Academy of Medical Sciences, Beijing Key Laboratory of Drug Clinical Risk and Personalized Medication Evaluation, \\ Beijing 100730, China \\ ${ }^{2}$ Faculty of Environmental Science and Engineering, Kunming University of Science and Technology, Kunming 650500, China \\ Correspondence should be addressed to Shuo Xu; victoria06251226@163.com
}

Received 29 April 2020; Revised 8 July 2020; Accepted 15 July 2020; Published 13 August 2020

Guest Editor: Tapan Sarkar

Copyright $\odot 2020$ Shuo Xu et al. This is an open access article distributed under the Creative Commons Attribution License, which permits unrestricted use, distribution, and reproduction in any medium, provided the original work is properly cited.

\begin{abstract}
A series of ultrathin $\mathrm{BiOCl} 2 \mathrm{D}$ nanosheet photocatalysts were prepared by the TBAOH-assisted hydrolysis method in water. The effects of tetrabutylammonium hydroxide $(\mathrm{TBAOH})$ dosages, chlorine source, preparation $\mathrm{pH}$ value, ultrasonic treatment, and magnetic stirring on the photocatalytic degradation dynamics of carbamazepine were examined under visible-light irradiation to optimize the preparation parameters. It was found that ultrathin $\mathrm{BiOCl}$ prepared with TBAOH dosages of 1 mmol and chlorine source of $\mathrm{NaCl}$ in the $\mathrm{pH}$ of 2 upon magnetic stirring of $6 \mathrm{~h}$ displayed the highest photocatalytic degradation rate constant $\left(0.0038 \mathrm{~min}^{-1}\right)$ of carbamazepine, which is 7.6 times higher than that with the ordinary $\mathrm{BiOCl}$ (without TBAOH). To clarify the mechanism on the outstanding photocatalytic activity of ultrathin $\mathrm{BiOCl}$, the elemental composition/state, micromorphology, and separation efficiency of photogenerated electron-hole pairs were investigated by X-ray photoelectron spectroscopy (XPS), scanning electron microscope (SEM), and photoluminescence (PL). Results showed that the presence of oxygen vacancy, ultrathin nanosheet structure, and improved separation efficiency of photogenerated electron-hole pairs contributed to the excellent photocatalytic degradation activity of ultrathin $\mathrm{BiOCl}$. The obtained result provides a novel method to fabricate ultrathin $\mathrm{BiOCl}$ with excellent photocatalytic degradation activity of carbamazepine under visible-light irradiation.
\end{abstract}

\section{Introduction}

Pharmaceutical and personal care products (PPCPs) as a new type of pollutants have been of growing concerns because of the biological toxicity and biorefractory nature [1]. Particularly, an antiepileptic drug of carbamazepine is a typical representative of PPCPs [2]. Carbamazepine is hard to be degraded from current wastewater treatment processes and appears to be remarkably persistent in a variety of water bodies including surface water, effluent from sewage treatment plant, and even in drinking water. The presence of carbamazepine is always associated with chronic toxicity to human and ecological environment [3]. Therefore, it is urgent to find a green and environmentally friendly method to degrade carbamazepine in water.
Photocatalytic technology has been reported to effectively degrade environmental pollutants due to the production of highly active redox species, such as electron $\left(\mathrm{e}^{-}\right)$, hole $\left(h^{+}\right)$, hydroxyl radical $(\cdot \mathrm{OH})$, and superoxide radical $\left(\mathrm{O}_{2}^{-}\right)$[4-6]. Compared with the traditional physical adsorption method, the photocatalysis technology can not only completely mineralize many pollutants but also exhibit the advantages of simple operation, high efficiency, and low operation cost. More importantly, photocatalytic technology takes the green renewable energy solar energy as the driving force. Therefore, photocatalytic technology has been favored by researchers all over the world and is expected to become one of the effective methods to solve environmental crisis.

The core of photocatalytic technology is fabricating the efficient photocatalyst. Up to date, many new and efficient 
photocatalysts have been fabricated by researchers [7-11]. Bismuth oxychloride (BiOCl), as a new type of semiconductor materials, has attracted great attention due to its unique microstructure and good photocatalytic performance [12-14]. However, in practical applications, BiOCl still fails to respond to visible light, which restricted the application of solar energy to degrade environmental pollutants [15].

To fabricate visible-light-driven $\mathrm{BiOCl}$, many strategies have been explored. With the assistance of other semiconductors, $\mathrm{BiOCl}$ composite heterojunction was always constructed to improve the photocatalytic activity upon visible-light irradiation. For example, Dong et al. prepared $\mathrm{H}-\mathrm{TiO}_{2} / \mathrm{BiOCl}$ heterojunction with improved photocatalytic activity under the visible light by a facile solvothermal method [16]. Elemental doping is also an efficient method to improve the visible-light-driven photocatalytic activity of $\mathrm{BiOCl}$, since its intrinsic light absorption is improved. Recently, $\mathrm{Xu}$ et al. described a novel bulk doping strategy to extend the light by bulk W-doping of BiOCl [17]. However, these methods are associated with massive organic solvents, high cost, or cumbersome procedures.

This paper provided a new strategy to fabricate ultrathin $\mathrm{BiOCl} 2 \mathrm{D}$ nanosheets for efficient photocatalytic degradation of carbamazepine upon visible-light irradiation by regulating the growth process of $\mathrm{BiOCl}$. To optimize the preparation parameters, the effects of tetrabutylammonium hydroxide $(\mathrm{TBAOH})$ dosages, chlorine source, preparation $\mathrm{pH}$ value, ultrasonic treatment, and magnetic stirring on the photocatalytic degradation of carbamazepine were examined under visible-light irradiation. Finally, X-ray photoelectron spectroscopy (XPS), scanning electron microscope (SEM), and photoluminescence (PL) were employed to clarify the elemental composition/state, micromorphology, and separation efficiency of photogenerated electron-hole pairs of the as-prepared $\mathrm{BiOCl}$ samples.

\section{Experimental}

2.1. Preparation of Ultrathin BiOCl 2D Nanosheet Photocatalysts. BiOCl samples were synthesized using a facile hydrolysis method in water. Typically, TBAOH was dissolved in ultrapure water. Then, $1 \mathrm{mmol}$ of $\mathrm{Bi}\left(\mathrm{NO}_{3}\right)_{3} \cdot 5 \mathrm{H}_{2} \mathrm{O}$ and $\mathrm{KCl}$ was introduced to the above TBAOH solution with ultrasonic treatment or magnetic stirring. Then, the white suspension was agitated at atmospheric environment to obtain precipitates. Finally, the precipitates were collected, washed, and dried in an oven.

To evaluate the effects of TBAOH dosages on the photocatalytic activity of $\mathrm{BiOCl}$, the concentrations of TBAOH were set at $0,0.5,1$, and $2 \mathrm{mmol}$.

To evaluate the effects of chlorine source on the photocatalytic activity, $\mathrm{BiOCl}$ samples were prepared by the same procedure except that $\mathrm{KCl}$ was changed to $\mathrm{HCl}, \mathrm{NaCl}$, and choline chloride.

The $\mathrm{pH}$ value of catalyst preparation reaction solution was tested on 1,2 , and 3 by changing the $\mathrm{pH}$ value with $\mathrm{NaOH}$.
Furthermore, the ultrasonic treatment $(1,2$, and $3 \mathrm{~h})$ and magnetic stirring $(3,6$, and $12 \mathrm{~h})$ were also optimized.

$\mathrm{BiOCl}$ prepared in the optimal preparation conditions was denoted as ultrathin $\mathrm{BiOCl}$. And the $\mathrm{BiOCl}$ sample prepared without $\mathrm{TBAOH}$ ( $\mathrm{TBAOH}$ concentrations of 0 ) was denoted as ordinary BiOCl.

2.2. Characterization. The micromorphology of the samples was observed using SEM (America FEI, Quanta 200). XPS analysis (ESCALab250Xi, Al Ka) was used to examine the chemical composition and element state of the as-prepared $\mathrm{BiOCl}$ samples. The adventitious carbon signal (C1s peak) at $284.8 \mathrm{eV}$ as an internal standard was used to calibrate the shift of the binding energy. The separation efficiency of photogenerated electron-hole pairs was evaluated by the PL spectrums using an Edinburgh FLS980 fluorescence spectrophotometer.

2.3. Photocatalytic Activity. The photocatalytic performance was evaluated by photocatalytic degradation of carbamazepine solution $(2.5 \mathrm{mg} / \mathrm{L})$. A $300 \mathrm{~W}$ xenon lamp with a $420 \mathrm{~nm}$ filter was used as the visible light source of the experiment. The liquid phase photocatalytic degradation of carbamazepine was carried out in a $50 \mathrm{~mL}$ of beaker, which was placed in a water bath pot to maintain $25^{\circ} \mathrm{C}$ throughout the reaction process. To examine the photocatalytic activity of the as-prepared $\mathrm{BiOCl}, 0.04 \mathrm{~g}$ of photocatalyst powders was added in the above carbamazepine solution. Before illumination, the solution was stirred in the dark for an hour to achieve the equilibrium of adsorption-desorption between carbamazepine and $\mathrm{BiOCl}$ photocatalyst powders. Then, the solution was irradiated upon visible light. The carbamazepine solution was sampled every 30 minutes $(3 \mathrm{ml}$ each time), which underwent centrifugation to remove the photocatalyst powders. Finally, the residual concentration was measured using an ultraviolet visible spectrophotometer (UV-vis, Puxi TU-1901).

The kinetics of photocatalytic degradation was evaluated by the apparent pseudo-first-order model expressed by following equation:

$$
\ln \left(\frac{C_{0}}{C}\right)=k t,
$$

where $C_{0}, C$, and $k$ are the original carbamazepine concentration $(2.5 \mathrm{mg} / \mathrm{L})$, carbamazepine concentration at reaction time $t$, and pseudo-first-order degradation rate constant.

\section{Results and Discussion}

\subsection{Optimization of Preparation Parameters}

3.1.1. TBAOH Dosages. Figure 1 shows the effects of TBAOH dosages on the carbamazepine degradation kinetics. It can be seen that the addition of TBAOH promoted the carbamazepine degradation kinetics under the photocatalytic reaction of $\mathrm{BiOCl}$, as the degradation rate constant increased over the $\mathrm{BiOCl}$ samples prepared in the presence 


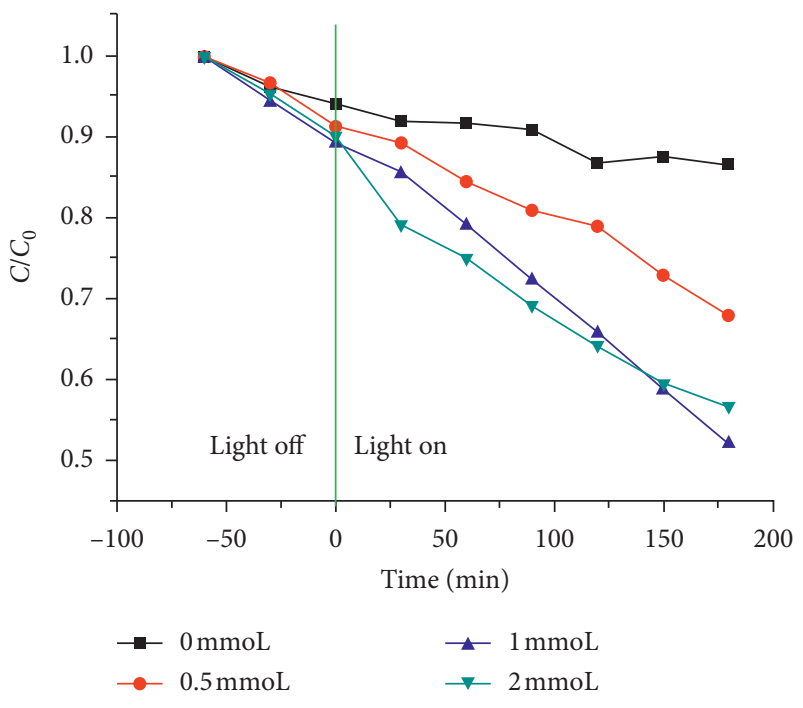

(a)

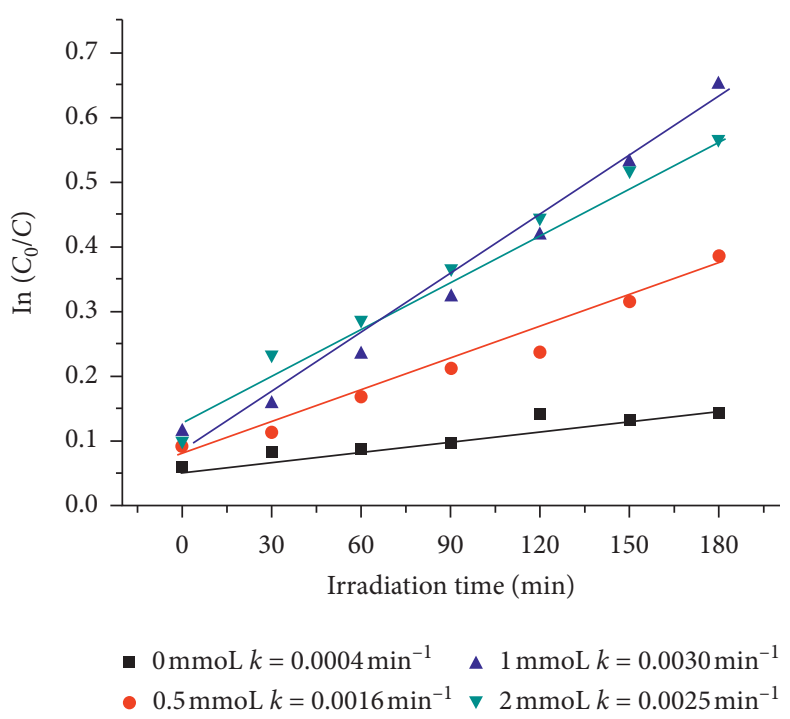

(b)

Figure 1: Effects of TBAOH dosages on the carbamazepine degradation kinetics.

of TBAOH. When the TBAOH dosages increased from 0.5 to $1 \mathrm{mmol}$, TBAOH displayed a positive effect on the degradation of carbamazepine with the degradation rate constant of carbamazepine increasing significantly from 0.0016 to $0.0030 \mathrm{~min}^{-1}$. However, the degradation kinetics became slow with a further increased TBAOH dosage from 1 to $2 \mathrm{mmol}$. The degradation rate constant of carbamazepine decreased to $0.0025 \mathrm{~min}^{-1}$ upon the excited $\mathrm{BiOCl}$ prepared by adding TBAOH of $2 \mathrm{mmol}$. To sum up, the highest degradation rate constant of carbamazepine was obtained at $0.0030 \mathrm{~min}^{-1}$. The absorption spectra for the degradation of carbamazepine at various times of irradiation are shown in Figure S1. As shown in the figure, the absorption spectra of carbamazepine decreased upon the light excited BiOCl. Hence, it is important to add TBAOH in the preparation procedure of $\mathrm{BiOCl}$ for the high degradation kinetics of carbamazepine. The role of TBAOH in regulating the growth process of $\mathrm{BiOCl}$ will be discussed further in the characterization results from XPS and SEM.

3.1.2. Chlorine Source. For the preparation of $\mathrm{BiOCl}$, both bismuth source and chlorine source were required. Because of low cost, $\mathrm{Bi}\left(\mathrm{NO}_{3}\right)_{3} \cdot 5 \mathrm{H}_{2} \mathrm{O}$ is the most widely used bismuth source, while chlorine source can be different based on the preparation route [18-21]. As reported in the literatures, $\mathrm{HCl}, \mathrm{NaCl}, \mathrm{KCl}$, and choline chloride can provide chlorine to the fabrication of $\mathrm{BiOCl}$. Chlorine source is important for the preparation of $\mathrm{BiOCl}$, for it can coordinate with bismuth source, control the concentration of reaction species in the reaction system, and influence the dynamic behavior in the process of $\mathrm{BiOCl}$ crystallization, finally affecting the microstructure and determining its photocatalytic performance. Here, the effects of chlorine sources on the photocatalytic activity of $\mathrm{BiOCl}$ were evaluated according to the degradation kinetics of carbamazepine.
Figure 2 presents the degradation kinetics of carbamazepine by $\mathrm{BiOCl}$ prepared with different chlorine sources. As exhibited, the degradation kinetics is the highest in $\mathrm{BiOCl}$ prepared using $\mathrm{NaCl}$ as chlorine source, with a degradation rate constant of $0.0038 \mathrm{~min}^{-1}$. The degradation rate constant of carbamazepine is $0.0018,0.0034$, and $0.0025 \mathrm{~min}^{-1}$ in the $\mathrm{BiOCl}$ prepared using $\mathrm{HCl}, \mathrm{KCl}$, and choline chloride as chlorine source, respectively. It should be noted that the difference in photocatalytic degradation kinetics of $\mathrm{BiOCl}$ prepared in various chlorine sources did not originate from the alteration of $\mathrm{pH}$ caused by chlorine source, as the $\mathrm{pH}$ was adjusted to the same value during the preparation of $\mathrm{BiOCl}$.

3.1.3. Effect of $p H$. Nucleation and crystallization process of $\mathrm{BiOCl}$ are highly dependent on the solution $\mathrm{pH}$ [22]. Hence, the effects of $\mathrm{pH}$ value within ranges of $1-3$ on the degradation activity of $\mathrm{BiOCl}$ were examined under visible-light irradiation. As shown in Figure 3, the highest degradation kinetics of carbamazepine was found in the $\mathrm{BiOCl}$ prepared in solution $\mathrm{pH}$ value of 2 . The degradation rate constant of carbamazepine is $0.0030,0.0033$, and $0.0031 \mathrm{~min}^{-1}$ in the $\mathrm{BiOCl}$ prepared in $\mathrm{pH}$ value of 1,2 , and 3 , respectively.

The $\mathrm{pH}$ of catalyst preparation reaction solution (bismuth nitrate $+\mathrm{TBAOH}$ ) was about 1 without adjustment (because of the existence of $\mathrm{TBAOH}$, the catalyst preparation reaction solution gave $\mathrm{pH} 1$ ). Then, $\mathrm{NaOH}$ was added into the reaction solution to adjust $\mathrm{pH}$ value from 2 to 3 . In the preparation of $\mathrm{BiOCl}$, it was found that white precipitates could be immediately formed after adding $\mathrm{NaOH}$ (the involved reaction is shown in the supplementary information files). Massive $\mathrm{NaOH}$ could speed up the nucleation and crystallization process excessively, which does not favor the controlled growth of $\mathrm{BiOCl}$. So, $\mathrm{NaOH}$ was added cautiously during the preparation of $\mathrm{BiOCl}$. And the $\mathrm{pH}$ values were tested within acid ranges of 1-3. 




(a)

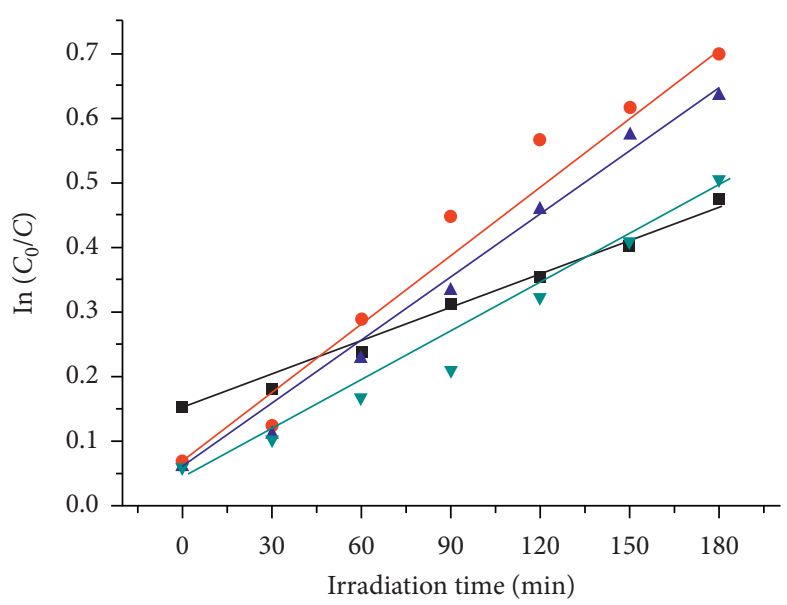

- $\mathrm{HCl} k=0.0018 \mathrm{~min}^{-1} \quad \boldsymbol{\Delta} \mathrm{KCl} k=0.0034 \mathrm{~min}^{-1}$

- $\mathrm{NaCl} k=0.0038 \mathrm{~min}^{-1} \quad \nabla$ Choline chloride $k=0.0025 \mathrm{~min}^{-1}$

(b)

FIGURE 2: Effects of chlorine source on the carbamazepine degradation kinetics.

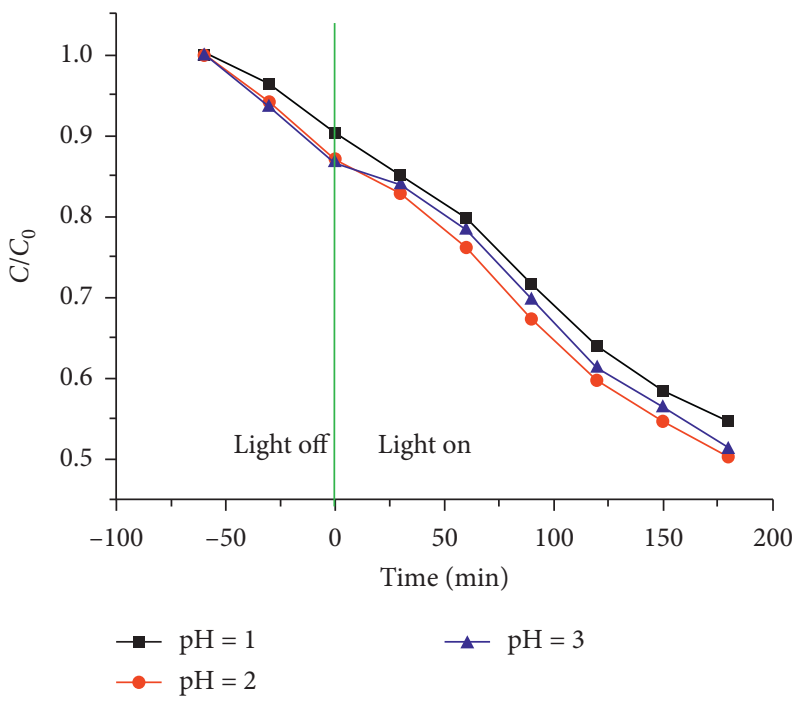

(a)

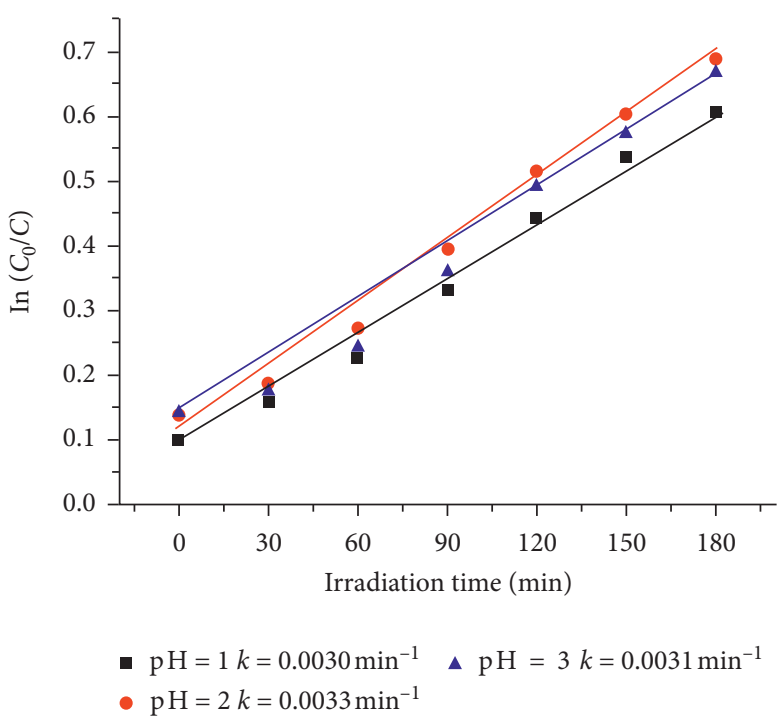

(b)

FIGURE 3: Effects of $\mathrm{pH}$ of reaction solution on the carbamazepine degradation kinetics.

3.1.4. Effect of Ultrasonic Treatment or Magnetic Stirring. Ultrasonic treatment or magnetic stirring is the ordinary treatment in the growth process of photocatalytic material [23-25]. Here, effects of ultrasonic treatment or magnetic stirring on the photocatalytic activity were also evaluated. As shown in Figure 4, different times of ultrasonic treatment were detected on 1,2 , and $3 \mathrm{~h}$. The highest degradation kinetics of carbamazepine was found in $\mathrm{BiOCl}$ prepared in ultrasonic treatment of $2 \mathrm{~h}$, with a degradation rate constant of $0.0035 \mathrm{~min}^{-1}$, which is higher than 0.0032 and $0.0029 \mathrm{~min}^{-1}$ for $\mathrm{BiOCl}$ prepared in ultrasonic treatment of 1 and $3 \mathrm{~h}$, respectively.
The magnetic stirring was also performed in the preparation of $\mathrm{BiOCl}$, as shown in Figure 5. The degradation rate constants are $0.0032,0.0038$, and $0.0037 \mathrm{~min}^{-1}$ in the $\mathrm{BiOCl}$ prepared in magnetic stirring of 3,6 , and $12 \mathrm{~h}$, respectively. Obviously, $\mathrm{BiOCl}$ prepared in magnetic stirring of $6 \mathrm{~h}$ exhibited the highest photocatalytic degradation rate constants of carbamazepine under visiblelight irradiation. This is also superior to the highest degradation rate constant of $0.0035 \mathrm{~min}^{-1}$ in the $\mathrm{BiOCl}$ prepared in ultrasonic treatment of $2 \mathrm{~h}$. Hence, magnetic stirring of $6 \mathrm{~h}$ was set as the optimal treatment in the growth process of $\mathrm{BiOCl}$. 


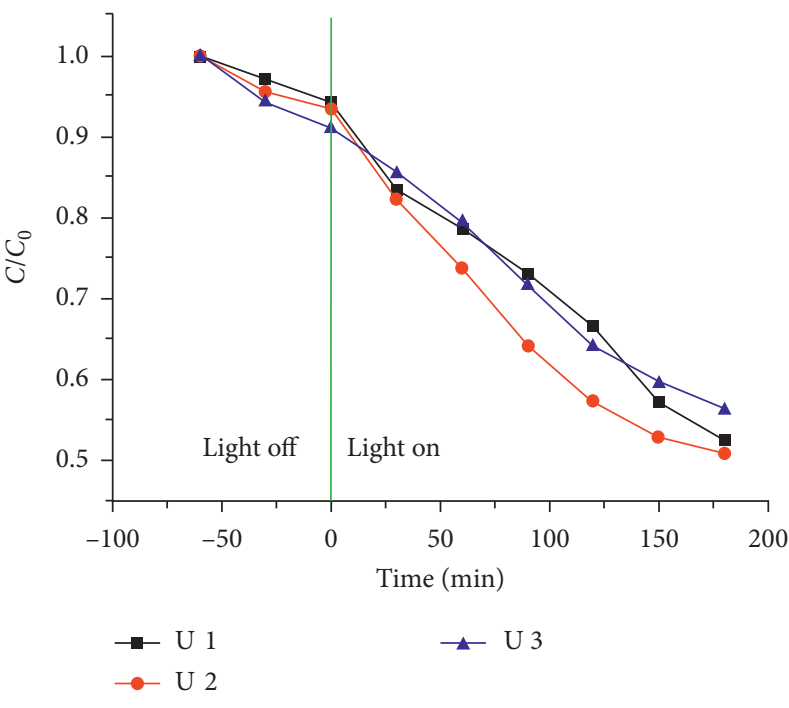

(a)

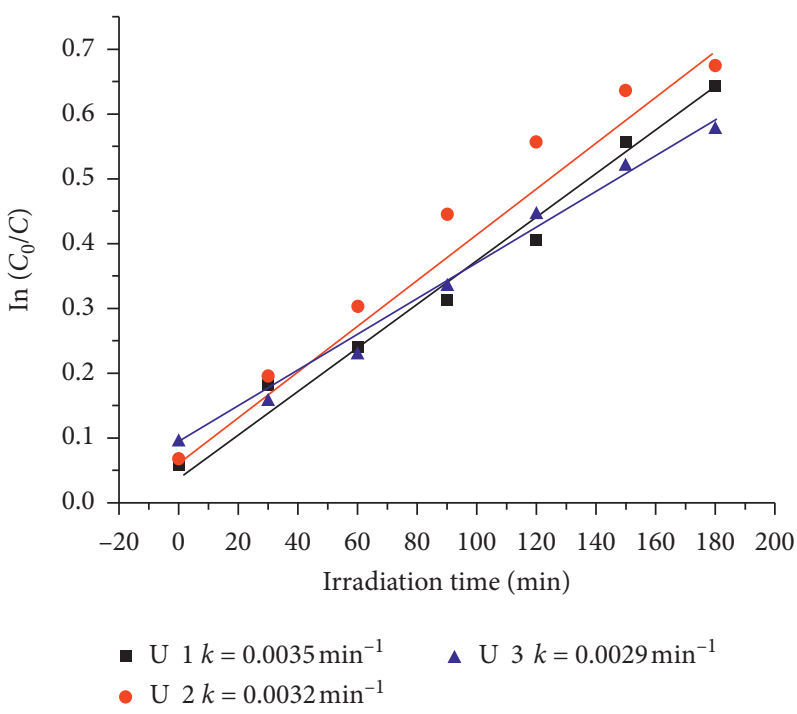

(b)

FIGURE 4: Effect of ultrasonic treatment on the carbamazepine degradation kinetics.



(a)

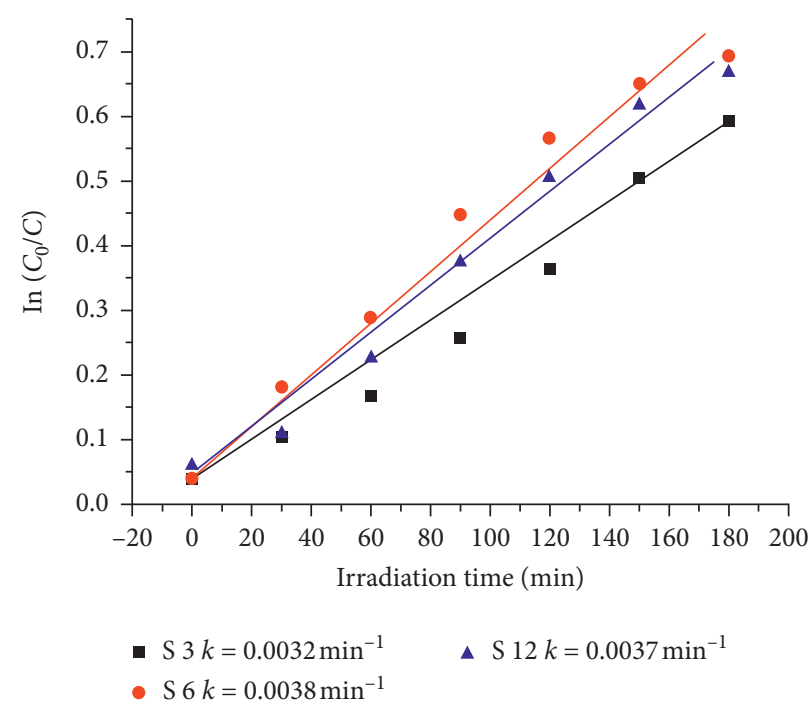

(b)

FIGURE 5: Effect of magnetic stirring on the carbamazepine degradation kinetics.

Taken together, the fastest degradation kinetics of carbamazepine can be obtained in the $\mathrm{BiOCl}$ prepared with TBAOH dosages of $1 \mathrm{mmoL}$ and chlorine source of $\mathrm{NaCl}$ in the $\mathrm{pH}$ of 2 upon magnetic stirring of $6 \mathrm{~h}$ (denoted as ultrathin $\mathrm{BiOCl}$ ). Ultrathin $\mathrm{BiOCl}$ displayed the highest photocatalytic degradation rate constant $\left(0.0038 \mathrm{~min}^{-1}\right)$ of carbamazepine, which is 7.6 times higher than that with the ordinary $\mathrm{BiOCl}$ (prepared without $\mathrm{TBAOH}$ ). To clarify the contributors to the outstanding photocatalytic activity, XPS, SEM, and PL were carried out to examine the elemental composition/ state, micromorphologies, and separation efficiency of photogenerated electron-hole pairs.

\subsection{Characterization}

3.2.1. Chemical Composition and Elemental State. The chemical composition and elemental state in the samples were determined by XPS analysis, as shown in Figure 6 . The XPS analysis suggested that only the elements of $\mathrm{Bi}, \mathrm{O}$, and $\mathrm{Cl}$ were found in the ordinary and ultrathin samples, which 


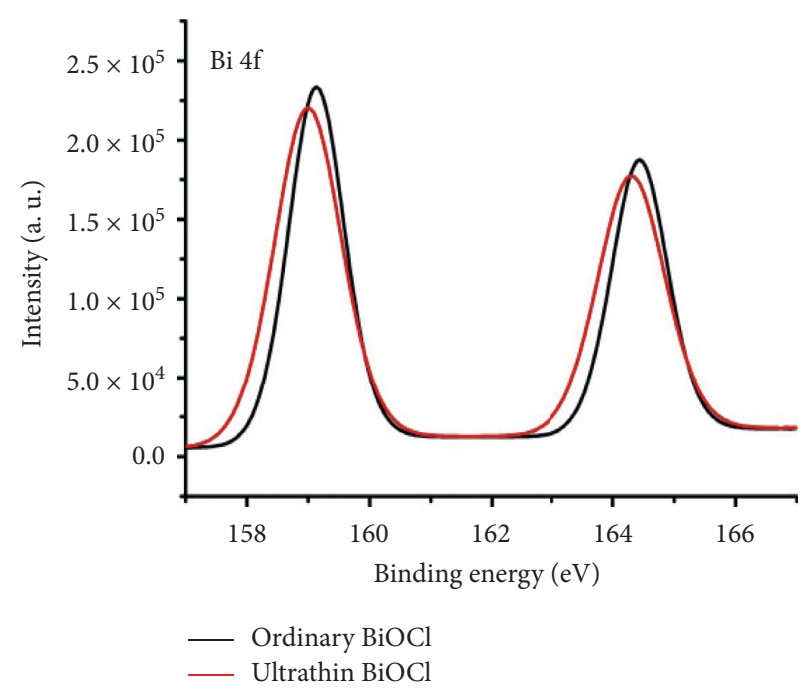

(a)

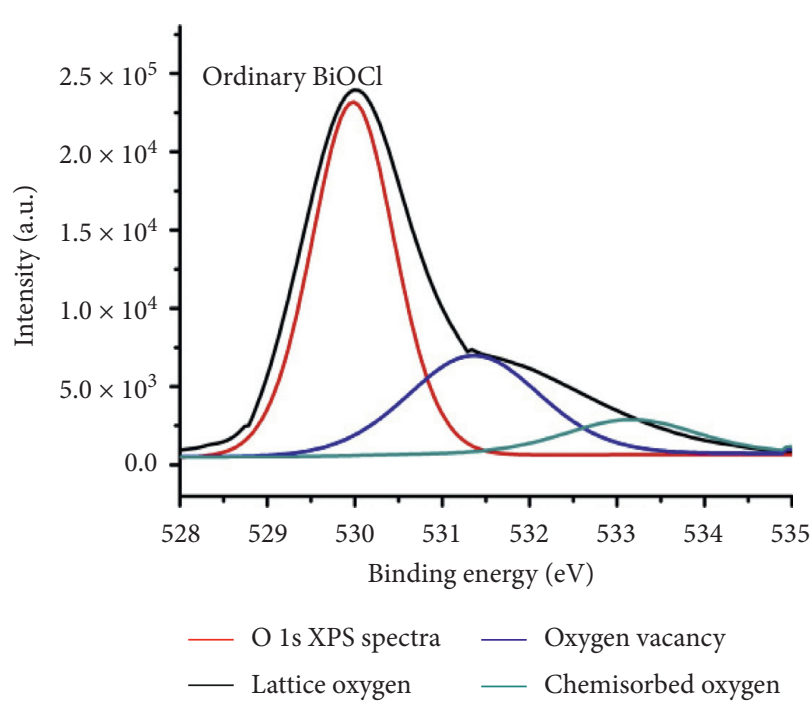

(c)

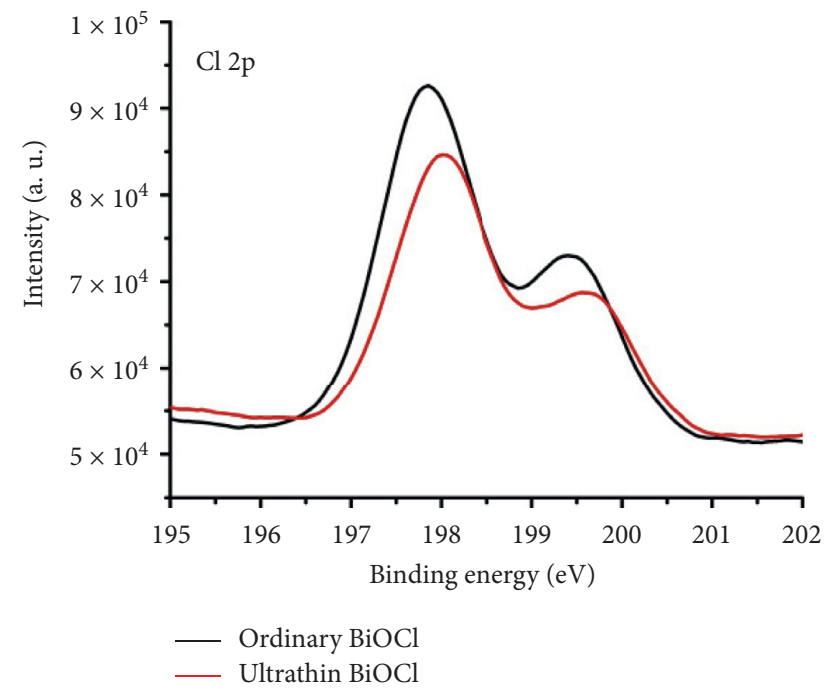

(b)

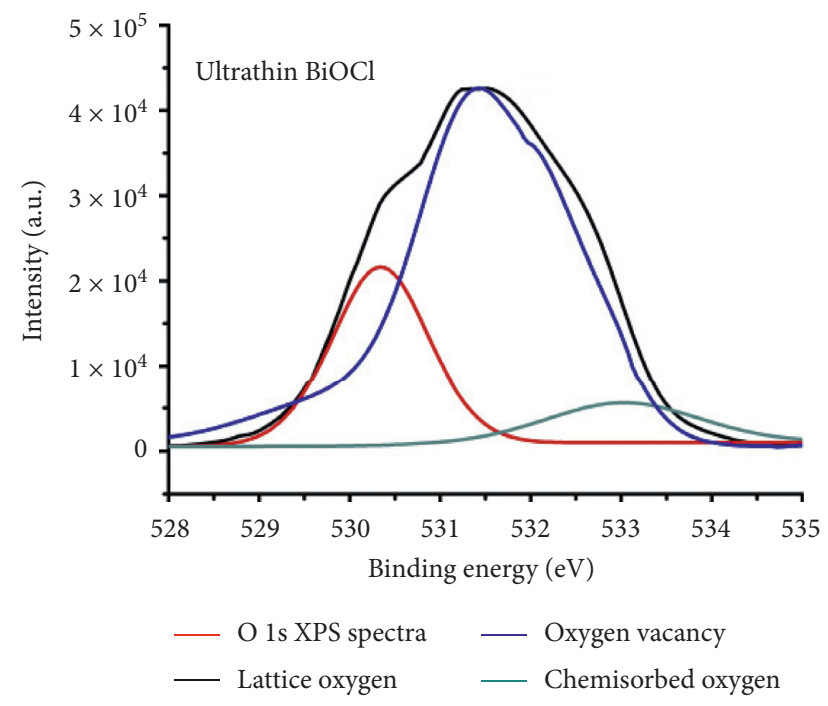

(d)

Figure 6: High-resolution $\mathrm{Bi} 4 \mathrm{f}(\mathrm{a}), \mathrm{Cl} 2 \mathrm{p}(\mathrm{b})$, and O1s (c, d) XPS spectra of ordinary BiOCl and ultrathin BiOCl.

confirmed the formation of $\mathrm{BiOCl}$ with high purity. The high-resolution spectra of $\mathrm{Bi} 4 \mathrm{f}, \mathrm{Cl} 2 \mathrm{p}$, and $\mathrm{O} 1$ s are shown in Figures 6(a)-6(d), respectively.

It can be seen from Figure 6(a) that the spectra of $\mathrm{Bi} 4 \mathrm{f}$ were deconvoluted into two peaks in both ordinary $\mathrm{BiOCl}$ and ultrathin $\mathrm{BiOCl}$. The two peaks were assigned to $\mathrm{Bi} 4 \mathrm{f} 5 / 2$ and $\mathrm{Bi} 4 \mathrm{f} 7 / 2$, respectively [26]. Compared with 159.2 and $164.5 \mathrm{eV}$ in ordinary $\mathrm{BiOCl}$, these two peaks shifted to lower binding energy of 159.0 and $164.3 \mathrm{eV}$ in ultrathin $\mathrm{BiOCl}$. Lower binding energy of $\mathrm{Bi}$ is classically attributed to the formation of lower charge $\mathrm{Bi}^{(3-x)+}$ ions caused by oxygen vacancies [27].

As shown in Figure 6(b), $\mathrm{Cl} 2 \mathrm{p}$ in ordinary $\mathrm{BiOCl}$ and ultrathin $\mathrm{BiOCl}$ samples also exhibited two peaks between 195.0 and $202.0 \mathrm{eV}$. The lower binding energy of $197.8 \mathrm{eV}$ in ordinary $\mathrm{BiOCl}$ and $198.0 \mathrm{eV}$ in ultrathin $\mathrm{BiOCl}$ corresponded to $\mathrm{Cl} 2 \mathrm{p} 1 / 2$, while $\mathrm{Cl} 2 \mathrm{p} 3 / 2$ was confirmed by the high binding energy of 199.4 and $199.7 \mathrm{eV}$ in ordinary $\mathrm{BiOCl}$ and ultrathin $\mathrm{BiOCl}$ samples, respectively [28]. Compared with ordinary $\mathrm{BiOCl}$, the two peaks of $\mathrm{Cl} 2 \mathrm{p} 1 / 2$ and $\mathrm{Cl} 2 \mathrm{p} 3 / 2$ shifted to relatively higher binding energy in the ultrathin $\mathrm{BiOCl}$ samples. The $\mathrm{Cl}$ peak at a higher binding energy may be explained by the following: $\mathrm{Cl}$ ions are more tightly bonded to ultrathin $\mathrm{BiOCl}$ due to the introduction of positively charged ions originated from the dissociation of TBAOH.

Figures 6(c) and 6(d) show the O1s spectra of ordinary $\mathrm{BiOCl}$ and ultrathin $\mathrm{BiOCl}$ samples, respectively. The $\mathrm{O} 1 \mathrm{~s}$ spectra can be deconvoluted into three peaks, namely, lattice oxygen, oxygen vacancy, and chemisorbed oxygen, which 
can be assigned to $530,531.4$, and $533.3 \mathrm{eV}$ in the ordinary $\mathrm{BiOCl}$ samples [29]. And the three peaks shifted to 530.3, 531.5 , and $533.1 \mathrm{eV}$ in ultrathin BiOCl. Obviously, the O1s peak became larger in the ultrathin $\mathrm{BiOCl}$ samples. Particularly, the intensity of peak assigned to oxygen vacancy improved significantly in ultrathin $\mathrm{BiOCl}$. This indicated that massive oxygen vacancies were introduced in the ultrathin $\mathrm{BiOCl}$ samples, which could be benefited from the addition of TBAOH. To further confirm the formation of the presence of oxygen vacancy, TPO was applied and is shown in Figure S2. As can be seen from the figure, both $\mathrm{BiOCl}$ samples show one peak centered at $87^{\circ} \mathrm{C}$, which could be attributed to the oxidation of cation vacancies [30]. And this peak became much larger in ultrathin $\mathrm{BiOCl}$ than that in ordinary $\mathrm{BiOCl}$, which indicated more oxygen vacancies in ultrathin BiOCl. This is in accordance with the XPS results. Taken together, both XPS and TPO confirm the formation of the presence of oxygen vacancy.

In the growth process of $\mathrm{BiOCl}, \mathrm{TBAOH}$ acted as a structure-directing agent inducing the formation of oxygen vacancies. This is similar to the previous reported triethanolamine (TEOA), which induced the production of oxygen vacancies on the surface of $\mathrm{BiOCl}$ nanosheets [31]. The presence of oxygen vacancies is favored for the reduction of oxygen molecule to produce massive active species, which are important for the photocatalytic degradation of carbamazepine [32].

3.2.2. Microstructure and Morphology. The XRD patterns of $\mathrm{BiOCl}$ samples are shown in Figure S3. As shown in the figure, both ordinary $\mathrm{BiOCl}$ and ultrathin $\mathrm{BiOCl}$ exhibited tetragonal structure (JCPDS No. 85-0861) with high purity (no other impurity diffraction peaks). SEM images were taken to examine the microstructure and morphology of the as-prepared samples. Figures $7(\mathrm{a})$ and $7(\mathrm{c})$ present the microstructure and morphology of ordinary $\mathrm{BiOCl}$ in different magnifications. And images in Figures 7(b) and 7(d) were taken for ultrathin BiOCl. As shown in the figures, both $\mathrm{BiOCl}$ samples were composed of $2 \mathrm{D}$ nanosheet-shaped structures. In comparison with ordinary $\mathrm{BiOCl}$, the nanosheets became much thinner and more uniform in ultrathin $\mathrm{BiOCl}$.

TEM images of ultrathin $\mathrm{BiOCl}$ and ordinary $\mathrm{BiOCl}$ are shown in the revised supplementary information files. As shown in Figure S4, the morphology of ultrathin $\mathrm{BiOCl}$ and ordinary $\mathrm{BiOCl}$ was composed by ultrathin nanosheets. In comparison with ordinary $\mathrm{BiOCl}$, the lower contrast in the TEM images of ultrathin $\mathrm{BiOCl}$ suggested the thinner thickness, which is consistent with the SEM results. The average thickness of samples was characterized to approximately $1.5 \mathrm{~nm}$ by atomic force microscope (AFM, Figure S5). This can be ascribed by the TBAOH participation in the growth process of $\mathrm{BiOCl}$. TBAOH can be dissociated to positively charged ions, facilitating its adsorption on the negative (001) plane. This retarded the (001) crystal growth and directed the formation of much thinner BiOCl nanosheets [21].

Generally, ultrathin $\mathrm{BiOCl}$ exhibits high surface area. The surface areas of $\mathrm{BiOCl}$ and $\mathrm{BiOCl}-\mathrm{T}$ were determined to be 9.64 and $20.32 \mathrm{~m}^{2} / \mathrm{g}$ for ordinary $\mathrm{BiOCl}$ and ultrathin $\mathrm{BiOCl}$, respectively. Larger surface area always means more active sites, so the improved surface area of ultrathin $\mathrm{BiOCl}$ could be favored for the photocatalytic degradation of carbamazepine.

\subsubsection{Separation of Photogenerated Electron-Hole Pairs.} The optical properties of ordinary $\mathrm{BiOCl}$ and ultrathin $\mathrm{BiOCl}$ photocatalysts were evaluated using UV-diffuse absorption spectra (DRS) technique, as shown in the supplementary information files (Figure S6). Obviously, the light absorption band edge shifted to the long wavelength region. To determine the visible-light responsibility, the energy gaps of the samples were calculated based on the UVvis DRS of the Kubelka-Munk function versus the photo energy. The energy gaps of the samples were estimated to be 2.98 and $3.20 \mathrm{eV}$ in ultrathin $\mathrm{BiOCl}$ and ordinary $\mathrm{BiOCl}$, respectively. The narrow band gap in ultrathin $\mathrm{BiOCl}$ can be ascribed to the existence of oxygen vacancy, which formed a new Bi $6 \mathrm{p}$ electronic state in the forbidden band of $\mathrm{BiOCl}$ [33].

Upon irradiation, photogenerated electron-hole pairs can be formed. The photocatalytic activities of semiconductor materials are highly dependent on the separation of photogenerated electron-hole pairs, which can be measured by PL spectrum. PL emission signal is originated from the recombination of photogenerated electron-hole pairs. Hence, the stronger emission signal in PL corresponded to the higher recombination efficiency of photogenerated electron-hole pairs [34].

Figure 8 shows the PL emission spectra of the ordinary $\mathrm{BiOCl}$ and ultrathin $\mathrm{BiOCl}$. As shown in the figure, ultrathin $\mathrm{BiOCl}$ displayed significantly diminished PL emission intensity. This indicated the decreased recombination rate of photogenerated electron-hole pairs and increased separation efficiency of photogenerated electron-hole pairs. Hence, the improved separation efficiency of photogenerated electronhole pairs contributed to the excellent photocatalytic activity of ultrathin BiOCl.

The photocatalytic degradation mechanism was systematically studied based on the different radical scavengers and $\mathrm{N}_{2}$ purging. As shown in Figure $\mathrm{S} 7, \mathrm{AgNO}_{3}$ decreased the photocatalytic degradation of $\mathrm{CBZ}$ indicating the importance of $\mathrm{e}^{-}$in the degradation reaction. The involvement of $h^{+}$was confirmed by the reduced photocatalytic degradation efficiency by adding HCOONa. Importantly, $\cdot \mathrm{OH}$ was produced in the CBZ degradation process, for IPA hampered the photocatalytic degradation of CBZ. In General, . $\mathrm{OH}$ is hard to be generated in $\mathrm{BiOCl}$ because of the more negative redox potential of $\mathrm{Bi}^{\mathrm{V}} / \mathrm{Bi}^{\mathrm{III}}(+1.59 \mathrm{eV})$ than $\cdot \mathrm{OH} / \mathrm{OH}(+1.99 \mathrm{eV})$. The production of $\cdot \mathrm{OH}$ in ultrathin $\mathrm{BiOCl}$ could be benefited from the ultrathin nanosheet structure, which shortens the transfer path of $\mathrm{e}^{-}$. This promoted the generation of $\cdot \mathrm{OH}$ through multielectron reduction of $\mathrm{O}_{2}$. In this reaction process, $\mathrm{O}_{2}$ is a crucial factor, which was supported by $\mathrm{N}_{2}$ purging. Taken together, the active species of $\mathrm{e}^{-}, h^{+}$, and $\cdot \mathrm{OH}$ dominated the photocatalytic degradation of $\mathrm{CBZ}$ over ultrathin $\mathrm{BiOCl}$. 

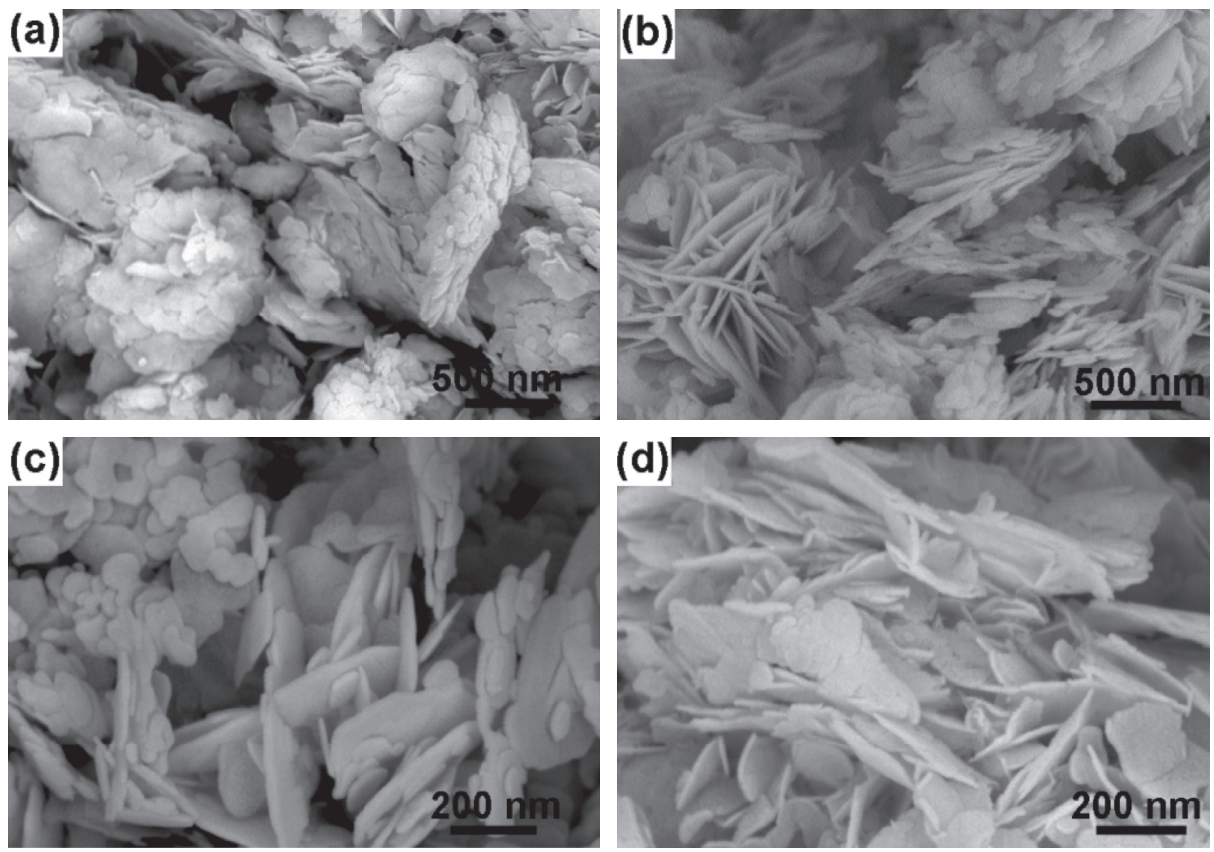

Figure 7: SEM images of ordinary $\operatorname{BiOCl}(a, c)$ and ultrathin $\mathrm{BiOCl}(b, d)$ samples.

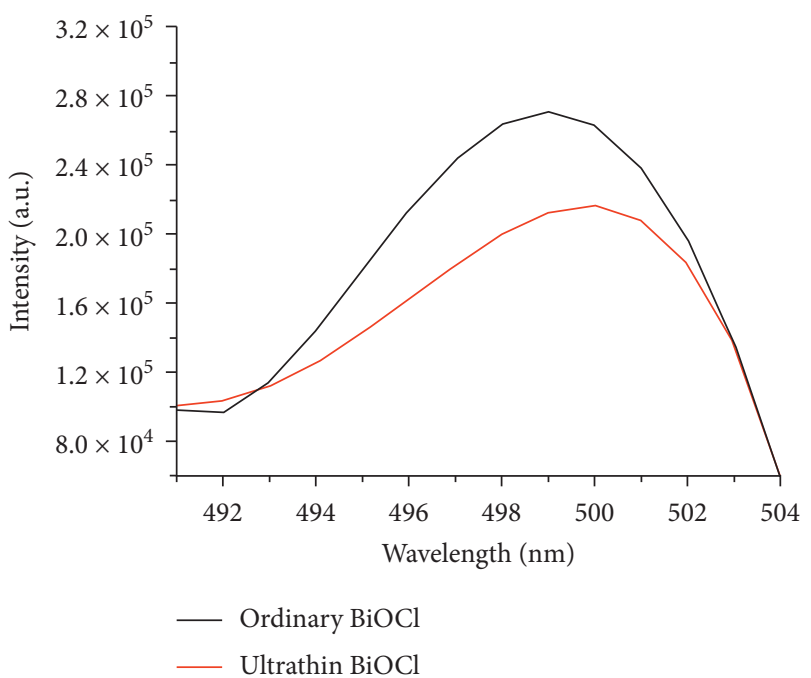

Figure 8: PL spectra of ordinary $\mathrm{BiOCl}$ and ultrathin $\mathrm{BiOCl}$ samples.

\section{Conclusions}

In summary, a series of ultrathin $\mathrm{BiOCl} 2 \mathrm{D}$ nanosheet photocatalysts were readily synthesized by the TBAOHassisted hydrolysis method in water. The preparation parameters were optimized to TBAOH dosages of $1 \mathrm{mmoL}$ and chlorine source of $\mathrm{NaCl}$ in the $\mathrm{pH}$ of 2 upon magnetic stirring of $6 \mathrm{~h}$. The obtained ultrathin $\mathrm{BiOCl}$ displayed the highest photocatalytic degradation rate constant $\left(0.0038 \mathrm{~min}^{-1}\right)$ of carbamazepine, which is 7.6 times higher than that with the ordinary $\mathrm{BiOCl}$. From the characterization of XPS, SEM, and PL, it was found that the presence of oxygen vacancy, ultrathin nanosheet structure, and improved separation efficiency of photogenerated electronhole pairs contributed to the excellent photocatalytic degradation activity of ultrathin $\mathrm{BiOCl}$. The obtained result provides a new strategy of regulating the growth process of $\mathrm{BiOCl}$ to fabricate ultrathin nanosheet structures with excellent photocatalytic degradation activity of carbamazepine under visible-light irradiation.

\section{Data Availability}

The experimental data used to support the findings of this study are included in the article. Other data are available from the corresponding author upon request.

\section{Conflicts of Interest}

The authors declare that they have no conflicts of interest.

\section{Authors' Contributions}

Shuo $\mathrm{Xu}$ and Xiaoya Gao contributed equally to this study.

\section{Acknowledgments}

The authors gratefully acknowledge the financial support of the High-Level Scientific Research Foundation for Talent Introduction (10978172).

\section{Supplementary Materials}

Figure S1: the absorption spectra for the degradation of carbamazepine over ultrathin $\mathrm{BiOCl}$. Figure S2: the absorption spectra for the degradation of carbamazepine over ultrathin $\mathrm{BiOCl}$. Figure S3: XRD patterns of the as-synthesized BiOCl samples. Figure S4: TEM images of the as- 
synthesized $\mathrm{BiOCl}$ samples. Figure S5: the average thickness of ultrathin $\mathrm{BiOCl}$ samples characterized by AFM. Figure S6: $\mathrm{UV}$-vis diffuse reflection spectra of the as-synthesized $\mathrm{BiOCl}$ samples. Figure S7: photocatalytic degradation CBZ over the as-synthesized $\mathrm{BiOCl}$ samples in the presence of various radicals scavengers. Figure S8: effect of initial $\mathrm{pH}$ on CBZ degradation. Figure S9: photocatalytic degradation CBZ over the $\mathrm{BiOCl}$ formed in the catalyst preparation reaction solution $\mathrm{pH}$ of 8 . (Supplementary Materials)

\section{References}

[1] C.-H. Shen, X.-J. Wen, Z.-H. Fei, Z.-T. Liu, and Q.-M. Mu, "Visible-light-driven activation of peroxymonosulfate for accelerating ciprofloxacin degradation using $\mathrm{CeO}_{2} / \mathrm{Co}_{3} \mathrm{O}_{4} \mathrm{p}-\mathrm{n}$ heterojunction photocatalysts," Chemical Engineering Journal, vol. 391, p. 123612, 2020.

[2] G. J. Akorede, S. F. Ambali, M. 1. G. Hudu et al., "Protective effect of vitamin $\mathrm{C}$ on chronic carbamazepine-induced reproductive toxicity in male wistar rats," Toxicology Reports, vol. 7, pp. 269-276, 2020.

[3] M. Nkoom, G. Lu, J. Liu, H. Yang, and H. Dong, "Bioconcentration of the antiepileptic drug carbamazepine and its physiological and biochemical effects on Daphnia magna," Ecotoxicology and Environmental Safety, vol. 172, pp. 11-18, 2019.

[4] X.-J. Wen, C.-H. Shen, C.-G. Niu et al., "Attachment of Ag/ $\mathrm{AgCl}$ nanoparticles on $\mathrm{CdMoO} 4$ microspheres for effective degradation of doxycycline under visible light irradiation: degradation pathways and mineralization activity," Journal of Molecular Liquids, vol. 288, p. 111063, 2019.

[5] D. Zhang, S. Liang, S. Yao et al., "Highly efficient visible/NIR photocatalytic activity and mechanism of $\mathrm{Yb} 3+/ \mathrm{Er} 3+\mathrm{co}-$ doped Bi4O5I2 up-conversion photocatalyst," Separation and Purification Technology, vol. 248, p. 117040, 2020.

[6] X.-J. Wen, C.-H. Shen, Z.-H. Fei et al., "Recent developments on AgI based heterojunction photocatalytic systems in photocatalytic application," Chemical Engineering Journal, vol. 383, p. 123083, 2020.

[7] D. Zhang, C. Su, H. Li, X. Pu, and Y. Geng, "Synthesis and enhanced piezophotocatalytic activity of $\mathrm{Ag}_{2} \mathrm{O}$ / $\mathrm{K}_{0.5} \mathrm{Na}_{0.5} \mathrm{NbO}_{3}$ composites," Journal of Physics and Chemistry of Solids, vol. 139, p. 109326, 2020.

[8] S. Liang, D. Zhang, X. Yao et al., "Deposition-precipitation synthesis of $\mathrm{Yb}^{3+} / \mathrm{Er}^{3+}$ co-doped $\mathrm{BiOBr} / \mathrm{AgBr}$ heterojunction photocatalysts with enhanced photocatalytic activity under Vis/NIR light irradiation," Separation and Purification Technology, vol. 238, p. 116450, 2020.

[9] X.-J. Wen, Q. Qian-Lu, X.-X. Lv et al., "Photocatalytic degradation of sulfamethazine using a direct Z-Scheme AgI/ $\mathrm{Bi}_{4} \mathrm{~V}_{2} \mathrm{O}_{11}$ photocatalyst: mineralization activity, degradation pathways and promoted charge separation mechanism," Journal of Hazardous Materials, vol. 385, p. 121508, 2020.

[10] D. Kong, D. Yin, D. Zhang et al., "Noble metal-free 0D-1D $\mathrm{NiCoP} / \mathrm{Mn}_{0.3} \mathrm{Cd}_{0.7} \mathrm{~S}$ nanocomposites for highly efficient photocatalytic $\mathrm{H}_{2}$ evolution under visible-light irradiation," Nanotechnology, vol. 31, no. 30, p. 305701, 2020.

[11] D. Zhang, Y. Tang, X. Qiu et al., "Use of synergistic effects of the co-catalyst, $\mathrm{p}-\mathrm{n}$ heterojunction, and porous structure for improvement of visible-light photocatalytic $\mathrm{H}_{2}$ evolution in porous $\mathrm{Ni}_{2} \mathrm{O}_{3} / \mathrm{Mn}_{0.2} \mathrm{Cd}_{0.8} \mathrm{~S} / \mathrm{Cu}_{3} \mathrm{P} @ \mathrm{Cu}_{2} \mathrm{~S}$," Journal of Alloys and Compounds, vol. 845, Article ID 155569, 2020.
[12] H. Liu, J. Huang, J. Chen, J. Zhong, J. Li, and D. Ma, "Influence of different solvents on the preparation and photocatalytic property of $\mathrm{BiOCl}$ toward decontamination of phenol and perfluorooctanoic acid," Chemical Physics Letters, vol. 748, p. 137401, 2020.

[13] J. Wang and Z. Zhang, "Co-precipitation synthesis and photocatalytic properties of $\mathrm{BiOCl}$ microflowers," Optik, vol. 204, p. 164149, 2020.

[14] Y. Wang, Y. Wang, X.-m. Song, Y. Zhang, and T. Ma, "BiOClbased photocathode for photocatalytic fuel cell," Applied Surface Science, vol. 506, p. 144949, 2020.

[15] Z. Long, G. Xian, G. Zhang, T. Zhang, and X. Li, "BiOCl$\mathrm{Bi}_{12} \mathrm{O}_{17} \mathrm{C}_{12}$ nanocomposite with high visible-light photocatalytic activity prepared by an ultrasonic hydrothermal method for removing dye and pharmaceutical," Chinese Journal of Catalysis, vol. 41, no. 3, pp. 464-473, 2020.

[16] H. Dong, M. Xiao, J. Li et al., "Construction of $\mathrm{H}-\mathrm{TiO}_{2} / \mathrm{BiOCl}$ heterojunction with improved photocatalytic activity under the visible and near-infrared light," Journal of Photochemistry and Photobiology A: Chemistry, vol. 392, p. 112369, 2020.

[17] K. Xu, J. Shen, D. Xu et al., "Molten-salt-mediated synthesis of bulk W doped BiOCl with highly enhanced visible-light photocatalytic performances," Applied Surface Science, vol. 495, p. 143595, 2019.

[18] F. T. Li, Q. Wang, X. J. Wang et al., "In-situ one-step synthesis of novel $\mathrm{BiOCl} / \mathrm{Bi}_{24} \mathrm{O}_{31} \mathrm{Cl}_{10}$ heterojunctions via self-combustion of ionic liquid with enhanced visible-light photocatalytic activities," Applied Catalysis B-Environmental, vol. 150-151, pp. 574-584, 2014.

[19] Y. Y. Wang, W. J. Peng, L. Y. Chai, and Y. H. Qin, "Study on preparation of sheet $\mathrm{BiOCl}$ powder by the method of bismuth nitrate transformation and hydrolysis," Hunan Metting. vol. 31, pp. 20-27, 2003.

[20] X. Zhang, Z. Ai, F. Jia, and L. Zhang, "Generalized one-pot synthesis, characterization, and photocatalytic activity of hierarchical $\mathrm{BiOX}(\mathrm{X}=\mathrm{Cl}, \mathrm{Br}, \mathrm{I})$ nanoplate microspheres," The Journal of Physical Chemistry C, vol. 112, no. 3, pp. 747-753, 2008.

[21] J. Ma, X. Liu, J. Lian, X. Duan, and W. Zheng, "Ionothermal synthesis of $\mathrm{BiOCl}$ nanostructures via a long-chain ionic liquid precursor route," Crystal Growth \& Design, vol. 10, no. 6, pp. 2522-2527, 2010.

[22] J. Jiang, K. Zhao, X. Xiao, and L. Zhang, "Synthesis and facetdependent photoreactivity of $\mathrm{BiOCl}$ single-crystalline nanosheets," Journal of the American Chemical Society, vol. 134, no. 10, pp. 4473-4476, 2012

[23] X. Gao, X. Zhang, Y. Wang, S. Peng, B. Yue, and C. Fan, "Rapid synthesis of hierarchical $\mathrm{BiOCl}$ microspheres for efficient photocatalytic degradation of carbamazepine under simulated solar irradiation," Chemical Engineering Journal, vol. 263, pp. 419-426, 2015.

[24] R. Li, J. Liu, X. Zhang et al., "Iodide-modified $\mathrm{Bi}_{4} \mathrm{O}_{5} \mathrm{Br}_{2}$ photocatalyst with tunable conduction band position for efficient visible-light decontamination of pollutants," Chemical Engineering Journal, vol. 339, pp. 42-50, 2018.

[25] J. Liu, R. Li, X. Zu et al., "Photocatalytic conversion of nitrogen to ammonia with water on triphase interfaces of hydrophilic-hydrophobic composite $\mathrm{Bi}_{4} \mathrm{O}_{5} \mathrm{Br}_{2}$ /ZIF-8," Chemical Engineering Journal, vol. 371, pp. 796-803, 2019.

[26] X. Gao, G. Tang, W. Peng, Q. Guo, and Y. Luo, "Surprise in the phosphate modification of $\mathrm{BiOCl}$ with oxygen vacancy: in situ construction of hierarchical Z-scheme BiOCl-OV-BiPO photocatalyst for the degradation of carbamazepine," Chemical Engineering Journal, vol. 360, pp. 1320-1329, 2019. 
[27] H. Li, J. Shi, K. Zhao, and L. Zhang, "Sustainable molecular oxygen activation with oxygen vacancies on the $\{001\}$ facets of $\mathrm{BiOCl}$ nanosheets under solar light," Nanoscale, vol. 6, no. 23, pp. 14168-14173, 2014.

[28] F. Dong, Y. Sun, M. Fu, W. Zhongbiao, and S.C. Lee, "Room temperature synthesis and highly enhanced visible light photocatalytic activity of porous $\mathrm{BiOI} / \mathrm{BiOCl}$ composites nanoplates microflowers," Journal of Materials Chemistry, vol. 219-220, pp. 26-34, 2012.

[29] Z. Song, X. Dong, N. Wang et al., "Efficient photocatalytic defluorination of perfluorooctanoic acid over $\mathrm{BiOCl}$ nanosheets via a hole direct oxidation mechanism," Chemical Engineering Journal, vol. 317, pp. 925-934, 2017.

[30] B. Bonnetot, V. Rakic, T. Yuzhakova, C. Guimon, and A. Auroux, "Preparation and characterization of $\mathrm{Me}_{2} \mathrm{O}_{3}-\mathrm{CeO}_{2}(\mathrm{Me}=\mathrm{B}, \mathrm{Al}, \mathrm{Ga}$, in) mixed oxide catalysts. 2 . Preparation by sol-gel method," Chemistry of Materials, vol. 20, pp. 1585-1596, 2008.

[31] X. Zeng, X. Gong, Y. Wan, R. He, and Z. Xu, "formation of oxygen vacancies on the $\{010\}$ facets of $\mathrm{BiOCl}$ and visible light activity for degradation of ciprofloxacin," Chemical Research in Chinese Universities, vol. 34, no. 5, pp. 711-718, 2018.

[32] X. Gao, W. Peng, G. Tang, Q. Guo, and Y. Luo, "Highly efficient and visible-light-driven $\mathrm{BiOCl}$ for photocatalytic degradation of carbamazepine," Journal of Alloys and Compounds, vol. 757, pp. 455-465, 2018.

[33] W. L. Huang, "Electronic structures and optical properties of $\mathrm{BiOX}(\mathrm{X}=\mathrm{F}, \mathrm{Cl}, \mathrm{Br}, \mathrm{I})$ via DFT calculations," Journal of Computational Chemistry, vol. 30, no. 12, pp. 1882-1891, 2009.

[34] Y. Lei, G. Wang, S. Song, W. Fan, and H. Zhang, "Synthesis, characterization and assembly of $\mathrm{BiOCl}$ nanostructure and their photocatalytic properties," CrystEngComm, vol. 11, no. 9, pp. 1857-1862, 2009. 